\title{
Management of Maxillary Premolar with Pre-eruptive Intracoronal Resorption: A 5-year Follow-up Case
}

\author{
Bourane Ambriss ${ }^{1}$, Carla Moukarzel ${ }^{2}$, Mohamed Ezzeddine ${ }^{3}$, Riad Bacho ${ }^{4}$
}

\begin{abstract}
Aim and objective: The present article aims to describe and discuss the preventive clinical management of a pre-eruptive intracoronal resorption (PEIR) defect on a maxillary right second premolar of an 11-year, 5-month-old girl.

Background: Pre-eruptive intracoronal resorption is described as an abnormal, well-circumscribed, radiolucent area, occurring within the coronal dentinal tissue close to the dentinoenamel junction of unerupted teeth and extending into various depths of the dentin. It is a rare anomaly occurring in primary and permanent dentitions. In the past, these defects were misdiagnosed as caries, and were therefore called "pre-eruptive caries" or "hidden caries". Currently, the most acceptable etiological hypothesis for PEIR is intracoronal resorption by the invasion of resorptive cells into the dentine through breakdowns in the enamel during crown formation. These lesions are often detected accidentally during routine dental radiographic examination.

Case description: A fissure sealant was applied to the affected tooth shortly after its eruption. Clinical and radiographical assessments were scheduled every 6 months for a period of 5 years and 5 months.

Conclusion: The preventive approach proved to be effective in preserving the tooth vital and asymptomatic with normal root development for the entire follow-up period.

Clinical significance: This article raises awareness about misdiagnosed PEIR in primary and permanent dentitions. A close inspection of radiographs, taken during routine visits and orthodontic check-ups, is important for early detection and proper management of such defects. Keywords: Case report, Intracoronal radiolucency, Intracoronal resorption, Occult caries, Pre-eruptive. International Journal of Clinical Pediatric Dentistry (2021): 10.5005/jp-journals-10005-1881
\end{abstract}

\section{BACKGROUND}

Pre-eruptive intracoronal resorption (PEIR) is an asymptomatic anomaly presenting an abnormal, well-circumscribed, radiolucent area, occurring within the coronal dentinal tissue close to the enamel-dentine junction of unerupted teeth. ${ }^{1-3}$

These developmental defects have been reported for the first time by Skillen in 1941 who described it as "intrafollicular caries". ${ }^{4}$ In earlier literature, the lesions were confused with caries and mistakenly referred to as "occult caries", "hidden caries", "developmental caries", or "pre-eruptive caries". 5,6 Nowadays, the terms used to describe this clinical condition are pre-erupted intracoronal radiolucency, pre-erupted intracoronal resorption, or pre-eruptive intracoronal dentin defect. ${ }^{6-8}$ Histologically, these lesions show a soft tissue with spindle shaped-cells similar to resorptive cells and fibrous connective tissue cells. ${ }^{9}$

PEIR defects are usually detected incidentally during routine dental radiographs or orthodontic consultations before the dental eruption. ${ }^{7,10}$ This condition has mostly been described in permanent teeth. To date, only two reports of PEIRs in primary teeth have been documented. ${ }^{11-13}$ PEIR has been reported in various countries with a subject prevalence of 0.2 and $27.3 \%$ and a tooth prevalence of 0.2 and $3.5 \%$ (Table 1). ${ }^{11}$ The prevalence of PEIR values varies depending on the tooth, dentition stage, type of radiographic imaging used, demographic factors, and age of the patient assessed. ${ }^{11,14,15}$ PEIR defects have been most commonly found in molars and premolars. ${ }^{6}$ However, other teeth, like canines, have been reported. ${ }^{16,17}$ Most of the time, a single tooth is affected in the same individual, but cases with several teeth have also been documented..$^{18-21}$ Defects are often located on the mesial or central aspects of the crown,

\begin{abstract}
${ }^{1-4}$ Department of Pediatric Dentistry and Dental Public Health, Faculty of Dental Medicine, Lebanese University, Beirut, Lebanon

Corresponding Author: Bourane Ambriss, Department of Pediatric Dentistry and Dental Public Health, Faculty of Dental Medicine, Lebanese University, Beirut, Lebanon, Phone: +9613632472, e-mail: b-ambriss@hotmail.com/bourane.ambriss@ul.edu.lb
\end{abstract}

How to cite this article: Ambriss B, Moukarzel C, Ezzeddine M, et al. Management of Maxillary Premolar with Pre-eruptive Intracoronal Resorption: A 5-year Follow-up Case. Int J Clin Pediatr Dent 2021;14(1):161-166.

Source of support: Nil

Conflict of interest: None

immediately adjacent to the amelodentinal junction and could extend to various depths of dentine thickness but rarely involve the pulp. ${ }^{11,16,22}$ Clinically, the crown appears to be intact. ${ }^{6}$

No association has been reported between PEIR and race, gender, medical conditions, systemic diseases, systemic factors, or the use of fluoride supplementation. ${ }^{23-25}$ However, a significant correlation was found between the ectopic position of teeth and PEIR. ${ }^{11,23}$

Many theories have been suggested for the etiology of PEIR. ${ }^{7,10,18,24}$ Nowadays, the most approved hypothesis is that it is an acquired defect, developmental in origin, resulting from an intracoronal resorption. ${ }^{18}$ The resorptive cells like osteoclasts, multinucleated giant cells, and chronic inflammatory cells invade the dentine through microperforations of the crown undergoing its formation. ${ }^{13,26-29}$ 
Pre-eruptive Intracoronal Resorption Defect

Table 1: Prevalence of pre-eruptive intracoronal resorption defects documented in some retrospective studies ${ }^{11}$

\begin{tabular}{|c|c|c|c|c|c|}
\hline Author/year & Country & Type of radiographs & $\begin{array}{l}\text { Subject prevalence (\%) } \\
(n / N)\end{array}$ & $\begin{array}{l}\text { Tooth prevalence (\%) } \\
(n / N)\end{array}$ & $\begin{array}{l}\text { Most common tooth } \\
\text { reported }\end{array}$ \\
\hline Seow et al. (1999) & Australia & Panoramic & $3(42 / 1,281)$ & $0.5(57 / 11,767)$ & Maxillary first molar \\
\hline Seow et al. (1999) & Australia & Bite wings & $6(126 / 1,959)$ & $2(163 / 9,919)$ & $\begin{array}{l}\text { Mandibular first } \\
\text { molar }\end{array}$ \\
\hline $\begin{array}{l}\text { Nik and Abul Rahman } \\
(2003)\end{array}$ & Malaysia & Panoramic & $27.3(275 / 1,007)$ & $2.1(309 / 14,554)$ & $\begin{array}{l}\text { Maxillary first } \\
\text { premolar }\end{array}$ \\
\hline $\begin{array}{l}\text { Özden and Acikgoz } \\
\text { (2009) }\end{array}$ & Turkey & Panoramic & $1.55(27 / 9,570)$ & $0.95(28 / 2,922)$ & $\begin{array}{l}\text { Mandibular second } \\
\text { molar }\end{array}$ \\
\hline $\begin{array}{l}\text { Al-Batayneh et al. } \\
\text { (2014) }\end{array}$ & Jordan & Panoramic & $8.1(128 / 1,571)$ & $0.62(128 / 20,788)$ & $\begin{array}{l}\text { Mandibular first } \\
\text { premolar }\end{array}$ \\
\hline Uzun et al. (2015) & Turkey & Panoramic & $0.7(40 / 5,554)$ & $\mathrm{N} / \mathrm{A}$ & Third molars \\
\hline $\begin{array}{l}\text { Demirtas et al. } \\
\text { (2016a) }\end{array}$ & Turkey & Panoramic vs CBCT & $\begin{array}{l}3.14(23 / 733) \text { vs } 9.5 \\
(70 / 4,096)\end{array}$ & $\begin{array}{l}3.14(23 / 733) \text { vs } \\
1.93(79 / 4,096)\end{array}$ & Third molars \\
\hline $\begin{array}{l}\text { Demirtas et al. } \\
\text { (2016b) }\end{array}$ & Turkey & $\mathrm{CBCT}$ & $15.1(42 / 278)$ & $3.5(48 / 1,384)$ & Third molars \\
\hline $\begin{array}{l}\text { Al-Tuwirqi and Seow } \\
\text { (2017) }\end{array}$ & Australia vs Saudi Arabia & Panoramic & $\begin{array}{l}0.2(14 / 842) \text { vs } 0.3 \\
(3 / 465)\end{array}$ & $\begin{array}{l}0.4(21 / 5,140) \text { vs } \\
0.2(5 / 3,217)\end{array}$ & $\begin{array}{l}\text { Mandibular second } \\
\text { molar }\end{array}$ \\
\hline $\begin{array}{l}\text { Manmontri et al. } \\
(2018)\end{array}$ & Thailand & Panoramic & $1.63(26 / 1,599)$ & $0.32(29 / 9,060)$ & $\begin{array}{l}\text { Mandibular second } \\
\text { molar }\end{array}$ \\
\hline
\end{tabular}

Seow had classified the PEIR defects into three types. In type I defect, the lesion involves less than one-third of the dentin thickness. In type II defect, the radiolucent area extends between one-third and two-thirds of the dentin thickness. As for type III, the defect expands beyond two-thirds of the width dentin thickness.,11

The management and the prognosis of teeth with PEIR depend on the extent of the lesion and the timing of its detection. ${ }^{8,9,16}$ Once PEIR is discovered, periodic radiographs should be taken to determine the nature of the lesion whether it is progressive (developing) or non-progressive (static). ${ }^{30,31}$ Therefore, a proper treatment plan can be adopted for each type. ${ }^{30}$ In the pre-eruptive stage, careful monitoring may be necessary when the defect is relatively small or if a tooth is nearly erupting. ${ }^{6}$ In some cases, where the lesion is large and progressive, surgical exposure of the unerupted tooth is needed to prevent pulp involvement. ${ }^{6,32}$ After the eruption, immediate intervention is required due to the fact that the affected tooth becomes very susceptible to the development of dental caries. ${ }^{5,32}$ The treatment modalities vary from fissure sealant to restorative treatment and could end up with more invasive procedures, such as endodontic therapy or extraction. ${ }^{5,6,8}$

This article aims to describe the clinical management of a PEIR-affected maxillary right second premolar of a young female patient, highlighting the importance of early diagnosis and periodic follow-up for a better prognosis.

\section{Case Description}

An 11-year, 5-month-old girl presented to our clinic with a chief complaint of discomfort on the right side of the maxilla. Her medical history was noncontributory. No history of dental trauma was reported. Extraoral examination revealed non-significant findings. Intraoral examination showed a mixed dentition with satisfactory oral hygiene. The maxillary right second primary molar (tooth no. 55) presented an important degree of mobility. Two bitewings confirmed the absence of interproximal caries and the complete radicular resorption of tooth no. 55. An intracoronal radiolucency on the unerupted maxillary right second premolar was detected

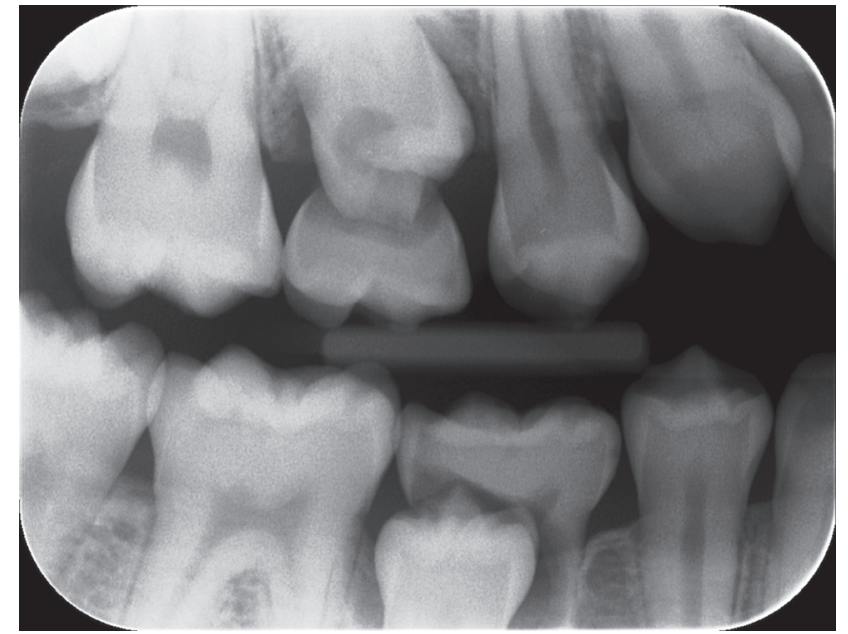

Fig. 1: Bitewing radiograph showing maxillary right second premolar with pre-eruptive intracoronal resorption defect with relation to the preceding primary molar

(Fig. 1). Based on clinical and radiographic aspects, the lesion was presumed to be a PEIR.

Considering the chief complaint, it was decided to extract tooth number 55 and to wait for the clinical eruption of the underlying PEIR-affected premolar. One month after the extraction, the PEIRaffected tooth has partially erupted. It was asymptomatic and had no caries or enamel defects with deep pits and fissures. Ostensibly, no differences were found between the affected premolar and the contralateral tooth. A control periapical radiograph was taken. The radiolucent area was oval-shaped extending from the middle to the distal portion of the crown underneath the occlusal dentinoenamel junction, reaching half of the dentin thickness (Fig. 2). Approximately two-thirds of the root length had developed with no periapical pathology. Preventive treatment was initiated immediately. Since the tooth has partially erupted, cotton rolls were 
placed instead of the rubber dam to obtain proper isolation. A resin sealant (Concise Light Cure White Sealant, 3M ESPE, St. Paul, MN, USA) was applied to the affected premolar. The other premolars were sealed as well for caries prevention (Fig. 3). A follow-up was scheduled every 6 months to monitor the tooth clinically and radiologically to determine the nature of the lesion and to assess the tooth development and the efficacy of the treatment provided.

When the patient was 12 years old, the clinical examination showed that the affected tooth had completely erupted with no symptoms reported. No alteration was observed in the sealant. A periapical radiograph proved that the lesion did not increase in size and normal root development was observed.

Twelve- and 18-month recall checkups revealed that the tooth remained vital and asymptomatic with no evidence of caries. The sealant was intact. During the radiographic examination, no changes were detected regarding the extent of the lesion. The root development process was uninterrupted (Fig. 4).

The patient complied with the first three follow-up appointments then she ceased to show up for 2 years and 5 months. At the age of 15 years, 5 months (approximately 4 years following diagnosis), the patient presented again to the clinic for a routine dental check-up. Clinically, the affected premolar was still symptom-free with no history of pain and responded positively to the electric pulp test and cold test. The fissure sealant was undamaged. Radiographically,

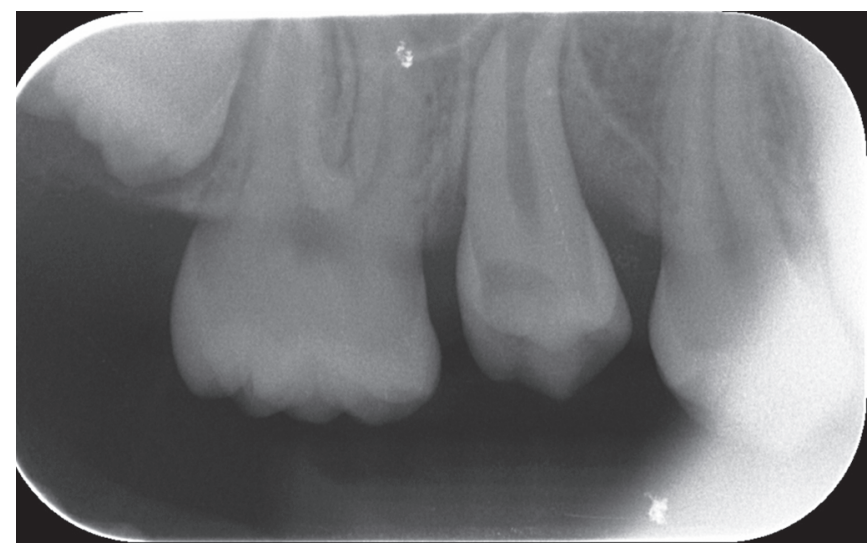

Fig. 2: Periapical radiograph showing the PEIR-affected premolar one month following the extraction of the preceding primary molar no progression of the lesion was noticed and a complete root development with the absence of periapical pathology was detected. Consequently, it was planned to continue following up the PEIR-affected premolar twice per year.

The latest recall appointment was when the patient was at 16 years, 11 months old. It showed no clinical or radiological changes on the affected tooth (Figs 5 and 6). The follow-up period (5 years and 5 months) proved that the preventive treatment was successful so far, and the type of the lesion is static.

\section{Discussion}

The present case describes an incidentally discovered and diagnosed asymptomatic, PEIR of a maxillary right second premolar on a bitewing radiograph. Pre-eruptive intracoronal resorption is defined as an abnormal, well-circumscribed, radiolucent area, occurring within the coronal dentinal tissue close to the dentinoenamel junction of unerupted teeth and extending into various depths of the dentin. ${ }^{1-3,26}$

Nevertheless, the intracoronal resorption of unerupted teeth has been encountered by dental practitioners for more than 70 years, the etiopathogenesis of this condition is still unknown. ${ }^{4,10,29}$ Diverse hypotheses have been proposed in the dental literature., ${ }^{70,18,24}$ These include the following: (a) an acquired pathological condition consequent of chronic periapical inflammation of preceding primary tooth occurring after coronal development. ${ }^{33-35}$ This theory has been rejected because, in most cases, the affected teeth do not have a primary precursor. ${ }^{18}(\mathrm{~b})$ Dental caries of the unerupted tooth. ${ }^{30,34}$ However, there are few evidences to support the hypothesis that cariogenic microorganisms can infect the developing tooth in its bony crypt. ${ }^{21,34}$ Therefore, the term "pre-eruptive caries" is not acceptable anymore..$^{10}$ (c) It has been postulated ${ }^{34,36}$ that the defect emerges when the dentine, with/without the enamel, fails to mineralize accurately during crown formation. $6,20,28$ since Seow and Hackley proved that the radiolucency became visible after the crown development is finished; they deduced that the lesion could not be the consequence of an intrinsic mineralization disturbance. ${ }^{20,37}$ (d) Currently, the most accepted hypothesis is that PEIR is caused by intracoronal resorption. ${ }^{13,18}$ It has been assumed that in the pre-eruptive stage, local damage to the reduced epithelium enamel of the tooth (Nasmyth's membrane) permits the inflammatory resorptive cells (multinucleated cells,
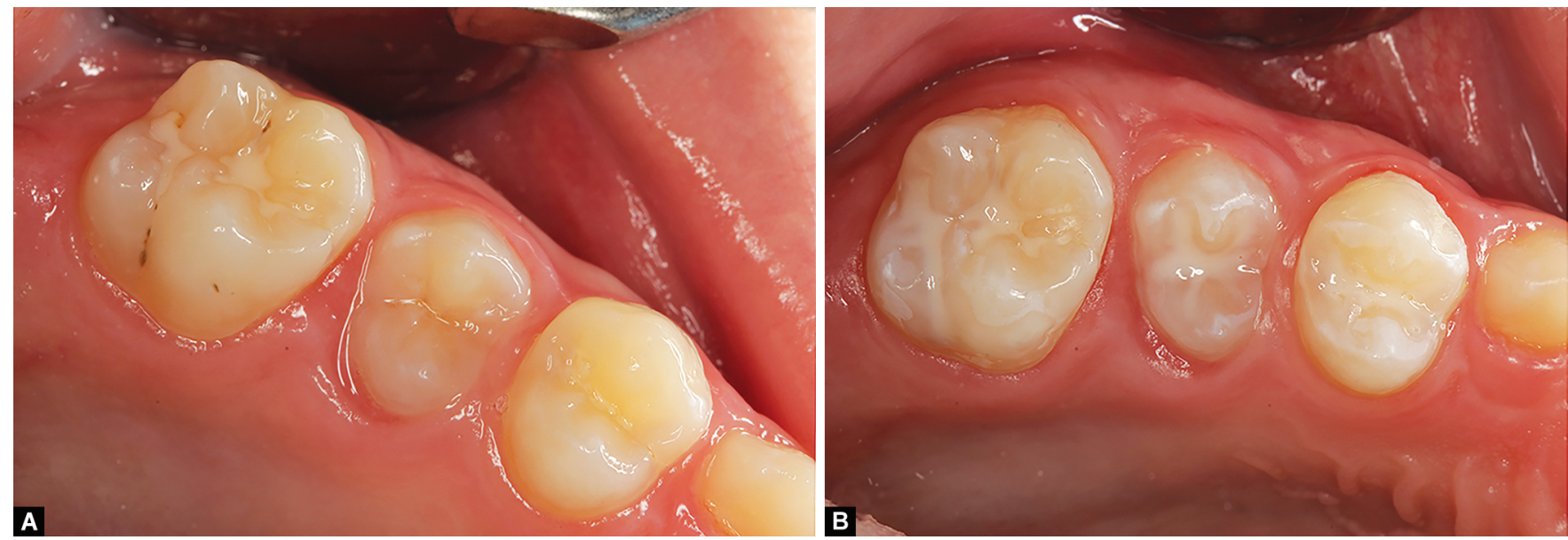

Figs $3 A$ and B: Photographs showing the PEIR-affected tooth before (A) and after (B) the fissure sealant application. The patient was 11 years and 6 months old 


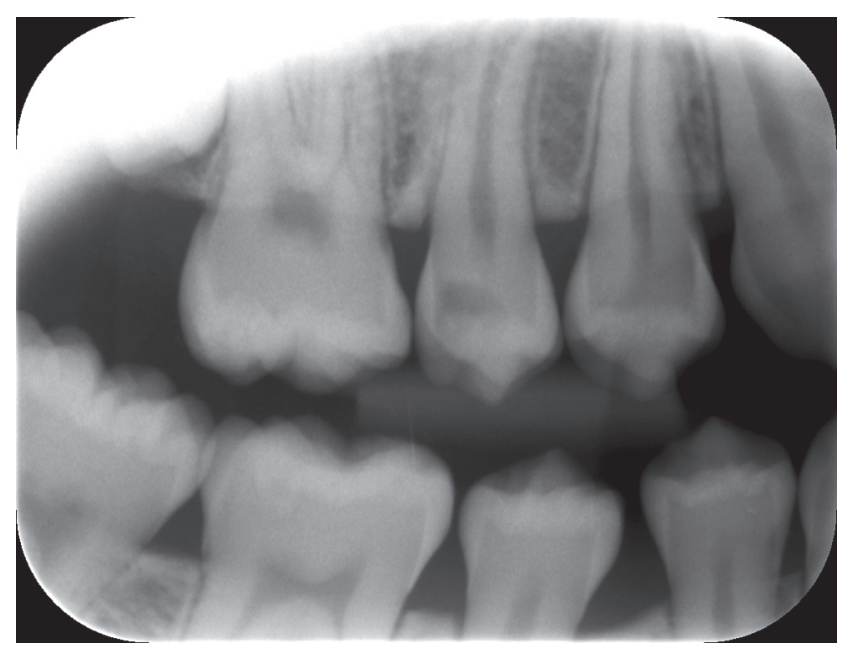

Fig. 4: A follow-up bitewing radiograph of the PEIR-affected premolar showing no evolution of the lesion. The patient was 12 years and 6 months old

osteoclasts, and other chronic inflammatory cells) to invade into the forming dentine, either through developmental breakdowns in the enamel or via communication close to the cementoenamel junction (CEJ). ${ }^{26-29,38}$ The origin of these resorptive cells is not the dental pulp. It could be the surrounding bone or the undifferentiated cells of the developing dental follicle. ${ }^{11,29,39}$

According to Seow, the loss of integrity of Nasmyth's membrane is caused by the abnormal local pressure encountered in the ectopic position of the affected tooth germ or the adjacent teeth. ${ }^{24,26}$ Thus, the ectopic position is considered to be a triggering factor for the initiation of intracoronal resorption. ${ }^{29,40}$ The affected tooth described in this report, as well as the adjacent teeth, are in a normal position.

The discrepancy in the prevalence values of PEIR depends on the tooth, the dentition stage, the type of radiograph used, the age of the patient, and the demographic factors. ${ }^{11,14,15}$ Premolars, second, and third molars show the highest prevalence of these defects, probably because these teeth are usually unerupted when panoramic radiographs are performed. ${ }^{23}$ However, clinical cases describing affected canines have also been reported. ${ }^{16,17}$ To date, only two cases have been documented in the primary dentition. ${ }^{11-13}$ The lack of PEIR cases reported in deciduous teeth is likely because routine dental radiographs are rarely taken before the age of 3 when normally all primary teeth had already erupted; by that time, many defects are indiscernible from dental caries and diagnosed as such. ${ }^{12,15,37}$ Most of the time, PEIR lesions are accidentally detected on various types of routinely prescribed radiographs, including bitewing, periapical, and panoramic radiographs. ${ }^{7,10,18}$ While some authors ${ }^{41}$ postulated that panoramic X-ray may lead to false-positive diagnosis due to the overlap with other structures, Nik and Abul Rahman ${ }^{42}$ recommended the use of this type of radiographs to detect defects on all unerupted teeth including third molars. Evidence shows that a higher prevalence of affected maxillary teeth was diagnosed when panoramic radiographs were used compared with bitewings. This is probably because bitewings taken during the mixed dentition might not always show unerupted premolars and maxillary molars in optimum view. ${ }^{1,11,20,30}$ In the present case, earlier detection of the lesion would have been possible if a panoramic radiograph was taken 2 years and 4 months before when the patient reported for a previous recall appointment

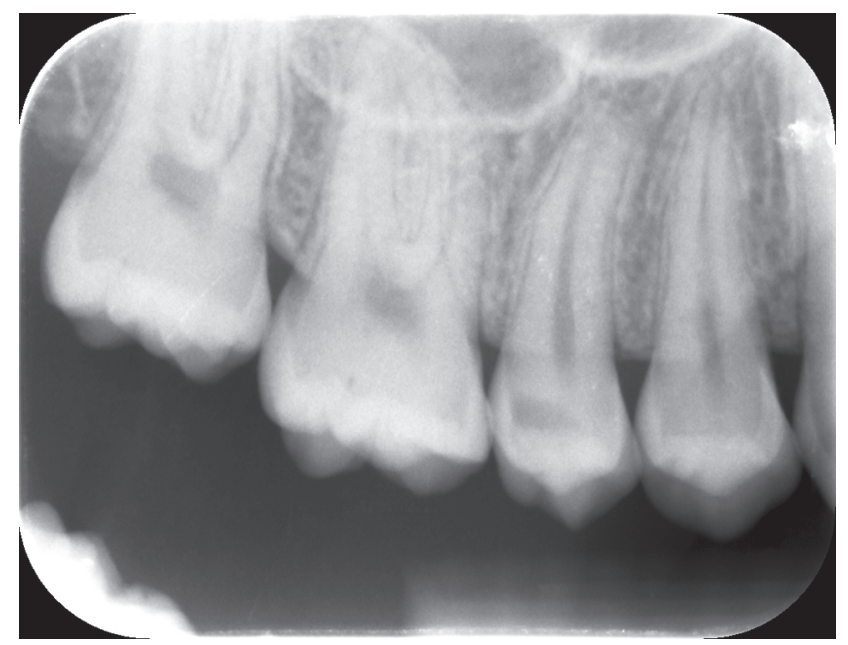

Fig. 5: Periapical radiograph five years and five months posttreatment. Note the static status of the defect and the normal root development of the affected tooth

(Fig. 7). On the other hand, Seow et al. documented a higher number of PEIR defects on bitewings compared with panoramic radiographs. ${ }^{1}$ Holan et al. recommended the use of the largest film size for bitewings. ${ }^{41}$ Furthermore, additional cases can be detected with cone-beam computed tomography (CBCT) than panoramic radiographs. ${ }^{11,20,22,29}$

The eruption mechanism of PEIR affected tooth sounds to be unimpaired. ${ }^{39}$ In fact, the premolar described in this case report erupted shortly after the extraction of the preceding primary molar.

Based on previous studies, there appears to be no correlation between PEIR and systemic factors, such as race, gender, or fluoride supplementation. ${ }^{23-25,43}$ However, Al-Tuwirqi and Seow found that this condition was associated with the ectopic position of the affected tooth or with delayed dental development of at least 6 months $5,23,32,43$ Özden and Acikgoz also stated a correlation with supernumerary teeth. ${ }^{11,40}$ In addition, Uzun et al. reported two clinical cases presenting simultaneously herpes zoster virus and PEIR defects. ${ }^{38}$

As observed in this case report, only one tooth with a PEIR defect was detected. This is in accordance with previous studies, that documented that a single tooth was involved in most of the cases, thus highlighting the role of local etiologic factors. ${ }^{30,38,40}$ However, more than one affected tooth in the same individual has been reported by other authors. ${ }^{44,45}$ Most of the time, PEIR occurs in a single location in the affected tooth. The distal location of the PEIR, in this case, is not similar to the finding by Al-Batayneh et al., who recognized most of the defects to appear mesially. ${ }^{19,30}$

According to the Seow classification system, the radiolucent area described in this report is classified as PEIR II defect, since it extends between one-third and two-thirds width of the dentin thickness. ${ }^{1,11,22}$ Many studies had found that PEIR I defects were the most common type. ${ }^{6,19}$ However, Seow et al. reported that half of all the lesions were PEIR III defects. ${ }^{19,37}$

The lesion progresses through the dentine in three-dimensional directions, weakening the enamel and could be stopped before reaching the pulp by the predentine layer. ${ }^{39}$ These defects are aseptic in the pre-eruptive stage of the tooth. ${ }^{29}$ While in the post-eruptive stage, it has been assumed that the resorbed area within the tooth crown tends to be secondarily colonized by microorganisms through an enamel defect or an extended 


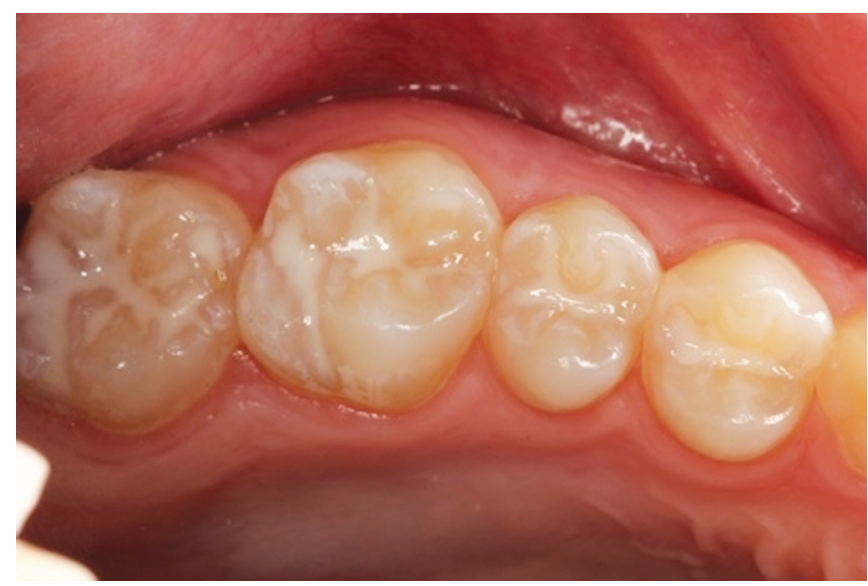

Fig. 6: Photograph showing the clinical aspect of the PEIR-affected tooth 5 years and 5 months posttreatment. The sealant is unimpaired

fissure that connects this lesion with the outer enamel surface. ${ }^{37,44}$ Although this communication may pass unnoticed, either clinically or radiographically, this does not exclude its existence. ${ }^{11,44}$ After bacterial infection, a dentine demineralization process, similar to that of the carious lesions, occurs in the asymptomatic lesion. As a consequence, this may stimulate pulp inflammation, and cause severe damage to the tooth structure. Hence, it the important to seal the lesion as soon as the tooth erupts without any prior excavation or cavity preparation. ${ }^{8,9,29}$ However, placing sealant over the occlusal surface without excavating the lesion may not be resistant enough to uphold and resist occlusal forces, and may put the tooth at risk of fracture of the undermined enamel, which will require a restoration later. ${ }^{7,8}$ Counihan and O'Connell described a similar case where the PEIR affected tooth was treated by fissure sealant and followed up for 5 years, but it ended up being fractured and restored with a stainless-steel crown. ${ }^{6,8}$ On the other hand, the total excavation of the intracoronal lesion and earlier restorative intervention may also result in a large opening of the occlusal surface of the tooth and could lead to fracture, restoration failure, secondary caries, or an iatrogenic pulp exposure, especially that the newly erupted tooth is characterized by a wide pulp chamber. ${ }^{7,8}$ Consequently, the longevity of this tooth may be endangered. ${ }^{7}$

After discussing with the parents, the advantages, and the risks of the two treatment options, the preventive approach was adopted with meticulous clinical and radiographic follow-up. Therefore, a fissure sealant was applied on the fully exposed occlusal surface of the premolar in question, as per Moskovitz and Holan, and Czarnecki et al. recommendations for type II PEIR defects. ${ }^{31,46}$ Based on some documented PEIR lesions that had significantly increased over 1 year, and on the AAPD guidelines that recommend a clinical judgment for cases similar to that of PEIR defects, a 6-month interval period of follow-up was decided in this reported case. ${ }^{45,47,48}$ During the recall appointments, the integrity of the sealant was assessed to prevent the susceptibility of carious lesions in the pit and fissures area. $^{6}$

Both clinical and radiographic examination revealed that the tooth continued its root development and was responding normally to all pulp vitality tests, confirming a healthy pulpal status. The series of dental radiographs taken during this follow-up period of 65 months were sufficient to diagnose the lesion as non-progressive or static type.

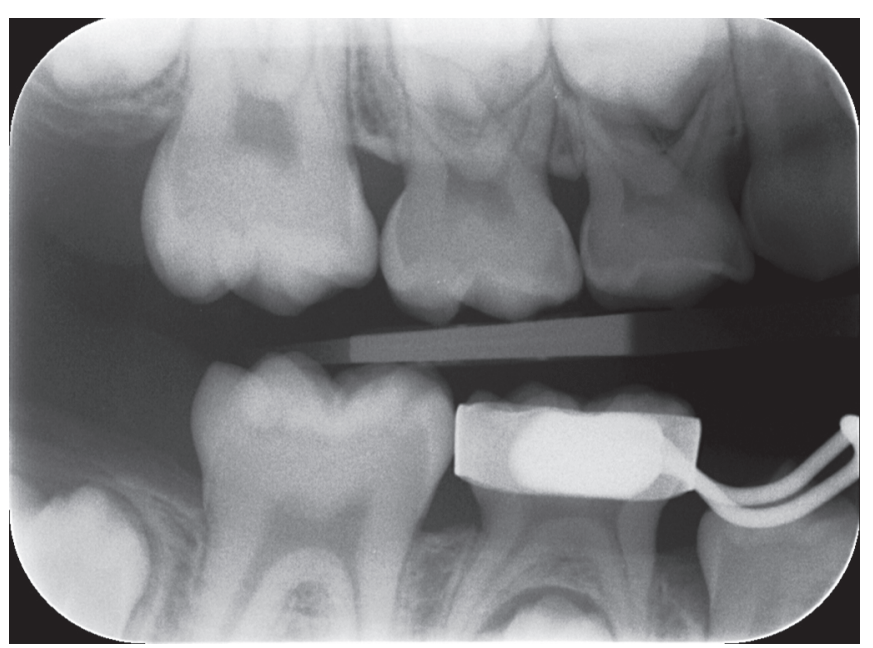

Fig. 7: Bitewing radiograph not showing the intracoronal resorption, taken when the patient was 9 years and 1 month old

\section{Conclusion}

Further investigation is required to understand the etiology and the pathogenesis of PEIR defects. Pediatric dentists and orthodontists are usually the first dental practitioners who evaluate intraoral and extraoral radiographs of unerupted teeth. Therefore, increased awareness of such lesions among them is crucial to improve diagnosis, provide early treatment, and prevent misdiagnosis.

\section{Clinical Significance}

Practitioners must take into consideration the possibility of encountering PEIR in primary and permanent dentitions. Meticulous radiographic examination, before and shortly after the eruption, is crucial for early detection and proper management of such lesions.

\section{References}

1. Seow WK, Lu PC, McAllan LH. Prevalence of pre-eruptive intracoronal dentine defects from panoramic radiographs. Pediatr Dent 1999;21(6):332-339.

2. Hemani K, Deepa G. Pre-eruptive intracoronal resorption - a review. Int J Curr Adv Res 2017;6(5):3589-3591. DOI: 10.24327/ ijcar.2017.3591.0322.

3. Rutar JE. Paediatric dentistry: coronal radiolucency. Case reports. Aust Dent J 1997;42(4):221-224. DOI: 10.1111/j.1834-7819.1997.tb00124.x.

4. Skillen WG. So-called intra-follicular caries. III Dent J 1941;10: 307-308.

5. Yang S, Kim J, Choi N, et al. Management of infected immature permanent tooth with pre-eruptive intracoronal resorption: two case reports. J Korean Acad Pediatr Dent 2017;44(2):220-227. DOI: https://doi.org/10.5933/JKAPD.2017.44.2.220.

6. Counihan KP, $\mathrm{O}^{\prime}$ Connell AC. Case report: pre-eruptive intra-coronal radiolucencies revisited. Eur Arch Paedia Dentis 2012;13(4):221-226. DOI: $10.1007 /$ BF03262874.

7. Manmontri C, Mahasantipiya PM, Chompu-inwai P. Preeruptive intracoronal radiolucencies: detection and nine years monitoring with a series of dental radiographs. Case Rep Dent 2017;2017:6261407. DOI: 10.1155/2017/6261407.

8. Spierer WA, Fuks AB. Pre-eruptive intra-coronal resorption: controversies and treatment options. J Clin Pediatr Dent 2014;38(4):326-328. DOI: 10.17796/jcpd.38.4.dm7652634h12705v. 
9. Moura BF, Silveira GR, Rodrigues-Junior SA. Diagnosis and clinical management of pre-eruptive intracoronal resorption - a case report. RSBO 2016;13(2):109-115. DOI: 10.21726/rsbo.v13i2.280.

10. Ilha MC, Kramer PF, Ferreira SH, et al. Pre-eruptive intracoronal radiolucency in first permanent molar. Int J Clin Pediatr Dent 2018;11(2):151-154. DOI: 10.5005/jp-journals-10005-1502.

11. Al-Batayneh OB, Al Tawashi EK. Pre-eruptive intra-coronal resorption of dentine: a review of aetiology, diagnosis, and management. Eur Archi Paediat Dent 2020;21(1):1-11. DOI: 10.1007/s40368-019-00470-4.

12. Schwimmer Y, Zeltser R, Moskovitz M. Deep caries due to pre-eruptive intracoronal resorption in a newly erupted primary molar. Int J Paediat Dentis 2017;27(4):313-315. DOI: 10.1111/ipd.12283.

13. Arwa G, Zilberman U. Diagnosis and management of pre-eruptive intra-coronal resorption (PICRL) in a primary molar tooth: a case report. J Dent App 2016;3(3):330-332.

14. Brunet-Llobet LL, Lahor-Soler E, Miranda-Rius J. Oral pain due to severe pre-eruptive intracoronal resorption in permanent tooth. Eur J Paediat Dentis 2014;15(3):332-334.

15. Omar S, Choi J, Nelson B, et al. Pre-Eruptive intracoronal resorption (PEIR): literature review and case report. CDA J 2015;43(5):255-260.

16. Manan NM, Mallineni SK, King NM. Case report: idiopathic preeruptive coronal resorption of a maxillary permanent canine. Eur Archi Paediat Dentis 2012;13(2):98-101. DOI: 10.1007/BF03262853.

17. Dowling PA, Fleming P, Corcoran F. A case report of preeruptive coronal resorption in a mandibular canine. Dent Update 1999;26(10):444-445. DOI: 10.12968/denu.1999.26.10.444.

18. De Souza NJ, Gopakumar MR, Hegde AM, et al. Pre-eruptive intra coronal lesions revisited: report of two rare cases and their treatment. Int J Contemp Med Res 2017;4(12):25-27.

19. De Souza N, Vaz A, Chalakkal P. Intracoronal radiolucency in an unerupted premolar: a rare occurrence. J Clin Diagnos Res 2017;11((1):4-5. DOI: 10.7860/JCDR/2017/22791.9135.

20. Demirtas O, Tarim Ertas E, Dane A, et al. Evaluation of pre-eruptive intracoronal resorption on cone-beam computed tomography: a retrospective study. Scanning 2016;38(5):442-447. DOI: 10.1002/ sca.21294.

21. Davidovich E, Kreiner B, Peretz B. Treatment of severe pre-eruptive intracoronal resorption of a permanent second molar. Pediat Dentis 2015;27(1):74-77.

22. Demirtas O, Dane A, Yildirim E. A comparison of the use of conebeam computed tomography and panoramic radiography in the assessment of pre-eruptive intracoronal resorption. Acta Odontol Scand 2016;74(8):636-641. DOI: 10.1080/00016357.2016.1235227.

23. Al-Tuwirqi A, Seow WK. A controlled study of pre-eruptive intracoronal resorption and dental development. J Clin Pediat Dent 2017;41(5):374-380. DOI: 10.17796/1053-4628-41.5.374.

24. Barra SG, Villalobos MIDOB, Penido CVDSR, et al. Pre-interruptive intracoronal resorption: clinical and radiographic follow-up. RGO, Rev Gaúch Odontol, Porto Alegre 2017;65(3):282-285. DOI: 10.1590/1981863720170002000163430.

25. Kane G, Cash A, Seehra J. Pre-eruptive coronal resorption of unerupted molar teeth in orthodontic patients. J Orthodont 2019. 1-7. DOI: 10.1177/1465312519838555.

26. Seow WK, Wan A, McAllan LH. The prevalence of pre-eruptive dentin radiolucencies in the permanent dentition. Pediatr Dent 1999;21(1):26-33.

27. Seow WK. Pre-eruptive intra-coronal resorption as an entity of occult caries. Pediatr Dent 2000;22(5):370-376.

28. Konde S, Sri Darshini CS, Agarwal M, et al. Unrevealed caries in unerupted teeth: a prevalence study. Contemp Clin Dent 2018;9(6):S305-S308. DOI: 10.4103/ccd.ccd_291_18.

29. Lenzi R, Marceliano-Alves MF, Alves F, et al. Pre-eruptive intracoronal resorption in a third upper molar: clinical, tomographic and histological analysis. Australian Dent J 2017;62(2):223-227. DOI: 10.1111/adj.12444.

30. Al-Batayneh OB, AlJamal GA, AITawashi EK. Pre-eruptive intracoronal dentine radiolucencies in the permanent dentition of Jordanian children. Eur Arch Paediatr Dent 2014;15(4):229-236. DOI: 10.1007/ s40368-013-0104-x.

31. Moskovitz M, Holan G. Pre-eruptive intra-coronal radiolucent defect: a case of a nonprogressive lesion. J Dent Child (Chic) 2004;71(2):175178.

32. Zilberman U, Hassan J, Leiboviz-Haviv S. Molar incisor hypomineralization and pre-eruptive intracoronal lesions in dentistry-diagnosis and treatment planning. World J Stomatol 2019;7(2):20-27. DOI: 10.5321/wjs.v7.i2.20.

33. Rankow H, Croll TP, Miller AS. Pre-eruptive idiopathic coronal resorption of permanent teeth in children. J Endod 1986;12(1):36-39. DOI: 10.1016/S0099-2399(86)80280-1.

34. Ignelzi Jr MA, Fields HW, White RP, et al. Intra-coronal radiolucencies within unerupted teeth. Case report and review of literature. Oral Surg Oral Med Oral Pathol 1990;70(2):214-220. DOI: 10.1016/00304220(90)90122-9.

35. Muhler JC. The effect of apical inflammation of the primary teeth on dental caries in the permanent teeth. J Dent Child 1957;25:156-159.

36. O'Neal KM, Gound TG, Cohen DM. Preeruptive idiopathic coronal resorption: a case report. J Endodon 1997;23(1):58-59. DOI: 10.1016/ S0099-2399(97)80210-5.

37. Seow WK, Hackley D. Pre-eruptive resorption of dentine in the primary and permanent dentitions: case reports and literature review. Pediatr Dent 1996;18(1):67-71.

38. Uzun I, Gunduz K, Canitezer G, et al. A retrospective analysis of prevalence and characteristics of pre-eruptive intracoronal resorption in unerupted teeth of the permanent dentition: a multicentre study. Int Endod J 2015;48(11):1069-1076. DOI: 10.1111/ iej.12404.

39. Becker A. Newsletter Archi Bull 2013. 24. Available at: https://www. dr-adrianbecker.com/page.php?pageld=281\&nlid=59.

40. Özden B, Acikgoz A. Prevalence and characteristics of intra-coronal resorption in unerupted teeth in the permanent dentition: a retrospective study. Oral Radiol 2009;25(1):6-13. DOI: 10.1007/s11282009-0003-3.

41. Holan G, Eidelman E, Mass E. Pre-eruptive coronal resorption of permanent teeth: report of three cases and their treatments. Pediatr Dent 1994;16(5):373-377.

42. Nik NN, Abul Rahman R. Pre-eruptive intra-coronal dentine defects of permanent teeth. J Clin Pediatr Dent 2003;27(4):371-375. DOI: 10.17796/jcpd.27.4.w26q821135440504.

43. Zilbermana U, Milevskib I, Yegorov D, et al. A 3000-year-old case of an unusual dental lesion: pre-eruptive intracoronal resorption. Archi Oral Biol 2019;97:97-101. DOI: 10.1016/j.archoralbio.2018.10.015.

44. Wood PF, Crozier DS. Radiolucent lesions resembling caries in the dentine of permanent teeth. A report of sixteen cases. Aust Dent J 1985;30(3):169-173. DOI: 10.1111/j.1834-7819.1985.tb04128.x.

45. Hata $H, A$ be $M$, Mayanagi $H$. Multiple lesions of intra-coronal resorption of permanent teeth in the developing dentition: a case report. Pediatr Dent 2007;29(5):420-425.

46. Czarnecki G, Morrow M, Peters M, et al. Pre-eruptive intracoronal resorption of a permanent first molar. J Dent Child (Chic) 2014;81(3):151-155.

47. Guideline on Prescribing Dental Radiographs for Infants. Children, adolescents, and persons with special health care needs. Pediatr Dent 2016;38(6):355-357.

48. Klambani M, Lussi A, Ruf S. Radiolucent lesion of an unerupted mandibular molar. Am J Orthod Dentofac Orthop 2005;127(1):67-71. DOI: 10.1016/j.ajodo.2004.01.020. 